\title{
Morphological Investigation of the Peripheral Distribution of Cutaneous Nerves in the Upper Extremity ${ }^{*}$
}

\author{
By \\ Tatsuo KASAI, Shoji CHIBA and Takahiko TSUNODA \\ Second Department of Anatomy, Hirosaki University \\ Medical School, Hirosaki 036, Japan \\ -Received for Publication, November 17, 1981-
}

Key words: Brachial plexus, Dermatome, Cutaneous vein, Upper extremity

Summary: The precise distribution of the cutaneous nerves in the upper extremity and the positional relations with respect to the superficial veins were examined in two adults and three mature fetuses. In the fetuses, a skin flap stripped from the underlying deep fascia was placed upside down in water to trace the cutaneous nerves under a stereoscopic microscope. By this method, all the cutaneous nerves could be followed peripheralwards as they entered the undersurface of the corium, preserving the entire course of the nerves without interruption. The results obtained were as follows.

1) Accoding to previous work by the authors, not only the muscular nerves of the brachial plexus but also the cutaneous ones could be classified into ventral and dorsal derivatives. The boundaries of distribution between the ventral and dorsal cutaneous nerves coincided with the course of the cephalic and basilic veins.

2) Overlapping of distribution between adjacent cataneous nerves could not be observed. Thus against Foerster's findings in the living body which demonstrated a broad overlap of distribution between cutaneous nerves, each cutaneous nerve had its own supply area, and no other nerves supplied the same region.

3) The course of the anterior axial line which had been observed physiologically as boundaries between discontinuous dermatomes, could be determined anatomically. In the proximal half of the arm, it coincided with the course of the cephalic vein.

The present investigation was designed to elucidate the precise distribution of the cutaneous nerves of the arm and forearm, and also to determine the positional relations with respect to the superficial veins of the upper extremity, especially the cephalic and basilic veins.

\section{Materials and Methods}

Ten cases of human upper extremity from two male adults and three mature fetuses were used. In the adults, all the cutaneous nerves of the arm and forearm were followed by routine methods after removing the superficial layer of the skin (Fig. 1). In the fetuses, after cutting the

\# This work was supported by a grant for scientific research from the Education Ministry of Japan. 
skin of the upper extremity longitudinally passing the mid-dorsal line, a whole layer of skin including the subcutaneous fat tissue was stripped off from the underlying deep fascia. In this procedure, some cutaneous nerves which were distributed to the dorsal surface of the upper extremity were of course cut; however, this did not fundamentally affect the study, because the nerves in the ventral surface of the arm and forearm remained intact as well as the two superficial veins. Next, the resected skin flap was placed in water upside down and all the nerves were dissected under a stereoscopic microscope. By this method, the nerves could be followed peripheralwards as far as they entered the deep surface of the corium, preserving the entire course of the nerve without interruption (Fig. 2).

\section{Results and Discussion}

1. Positional relations between the distribution of the cutaneous nerves and the superficial veins

As shown in Figs. 1 and 2, the brachial cutaneous branch of the medial antebrachial cutaneous nerve, which was termed the anterior brachial cutaneous nerve by Kasai (1966) (Cba), and the anterior branch of the intercostobrachial nerve (Icb-a) were distributed to the ventral surface of the arm, and their distributive area was bounded by the cephalic vein laterally and the basilic vein medially. The recurrent branch of the lateral antebrachial cutaneous nerve (Cal), when present as in Figs. 1 and 2, was also distributed in the ventral surface of the arm along the medial side of the cephalic vein. According to the present authors (1966, 1980), the three above-mentioned nerves originated from the ventral division of the brachial plexus; and it could be concluded therefore, that the distributive area of the ventral cutaneous nerves was bounded by the cephalic and the basilic veins. In other words, the course of these two superficial veins showed a border line of distribution be- tween the ventral and the dorsal cutaneous nerves of the arm.

On the other hand, the posterior branch of the intercostobrachial nerve (Icb-p), the medial brachial cutaneous nerve ( $\mathrm{Cbm}$ ) and all the brachial cutaneous branches of the axillary and the radial nerves were distributed in the dorsal surface of the arm, and their supply area was bounded by the cephalic and the basilic veins against the ventral region supplied with

\section{Abbreviations for Figures}

1: superior lateral brachial cutaneous nerve (axillary nerve)

2: inferior lateral brachial cutaneous nerve (radial nerve)

3: posterior antebrachial cutaneous nerve (radial nerve)

4: lateral antebrachial cutaneous nerve (musculocutaneous nerve)

5: anterior branch of medial antebrachial cutaneous nerve

6: ulnar branch of medial antebrachial cutaneous nerve

7: anterior brachial cutaneous nerve (of medial antebrachial cutaneous nerve)

8: medial brachial cutaneous nerve

9: anterior branch of intercostobrachial nerve

10: posterior branch of intercostobrachial nerve

11: posterior brachial cutaneous nerve (radial nerve)

A : anterior axial line

B : basilic vein

C : cephalic vein 

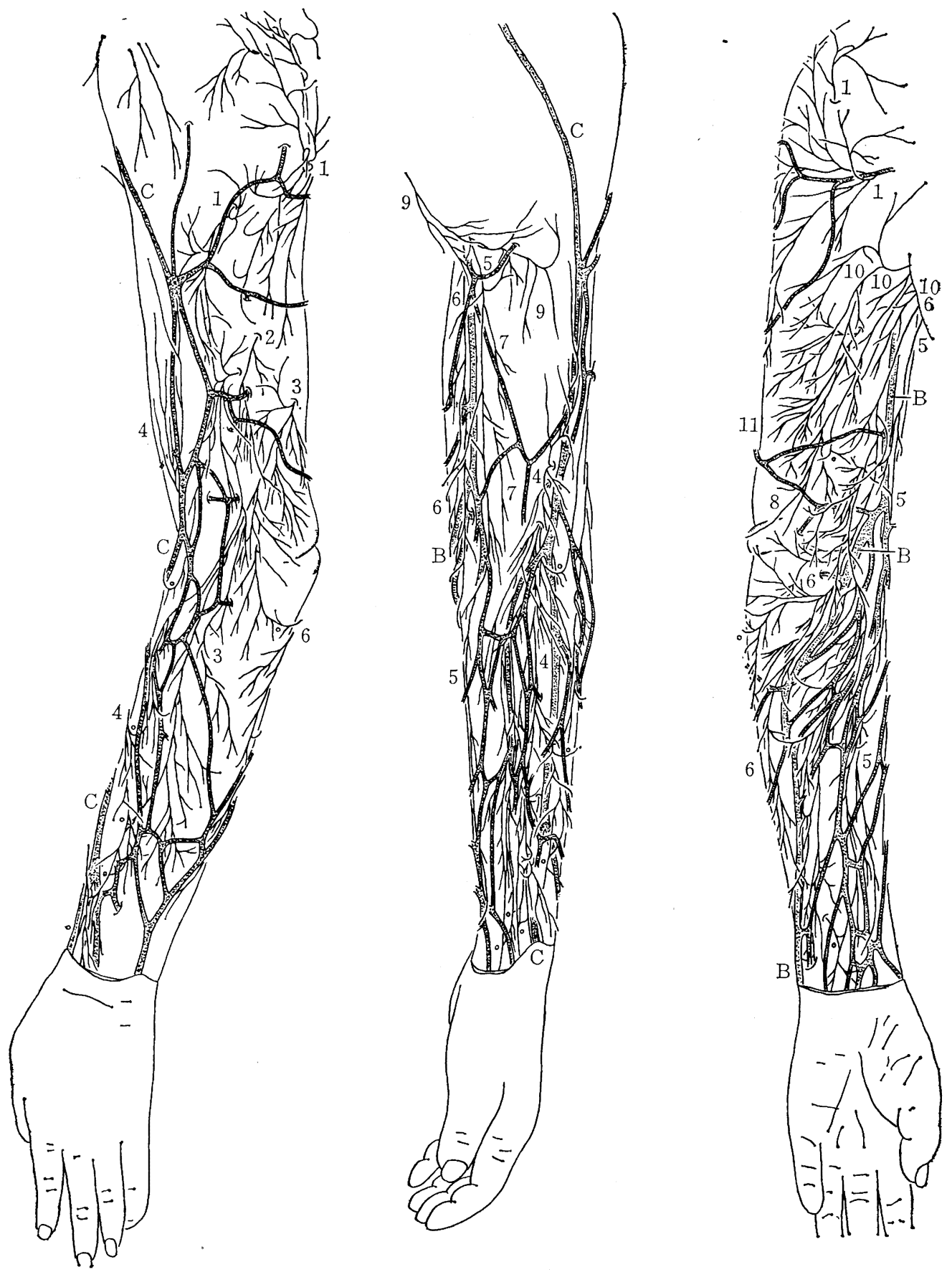

Fig. 1. Distribution of the cutaneous nerves and the positional relations with respect to the superficial veins. Left upper extremity of an adult. Lateral-, anterior- and medialviews are shown. 


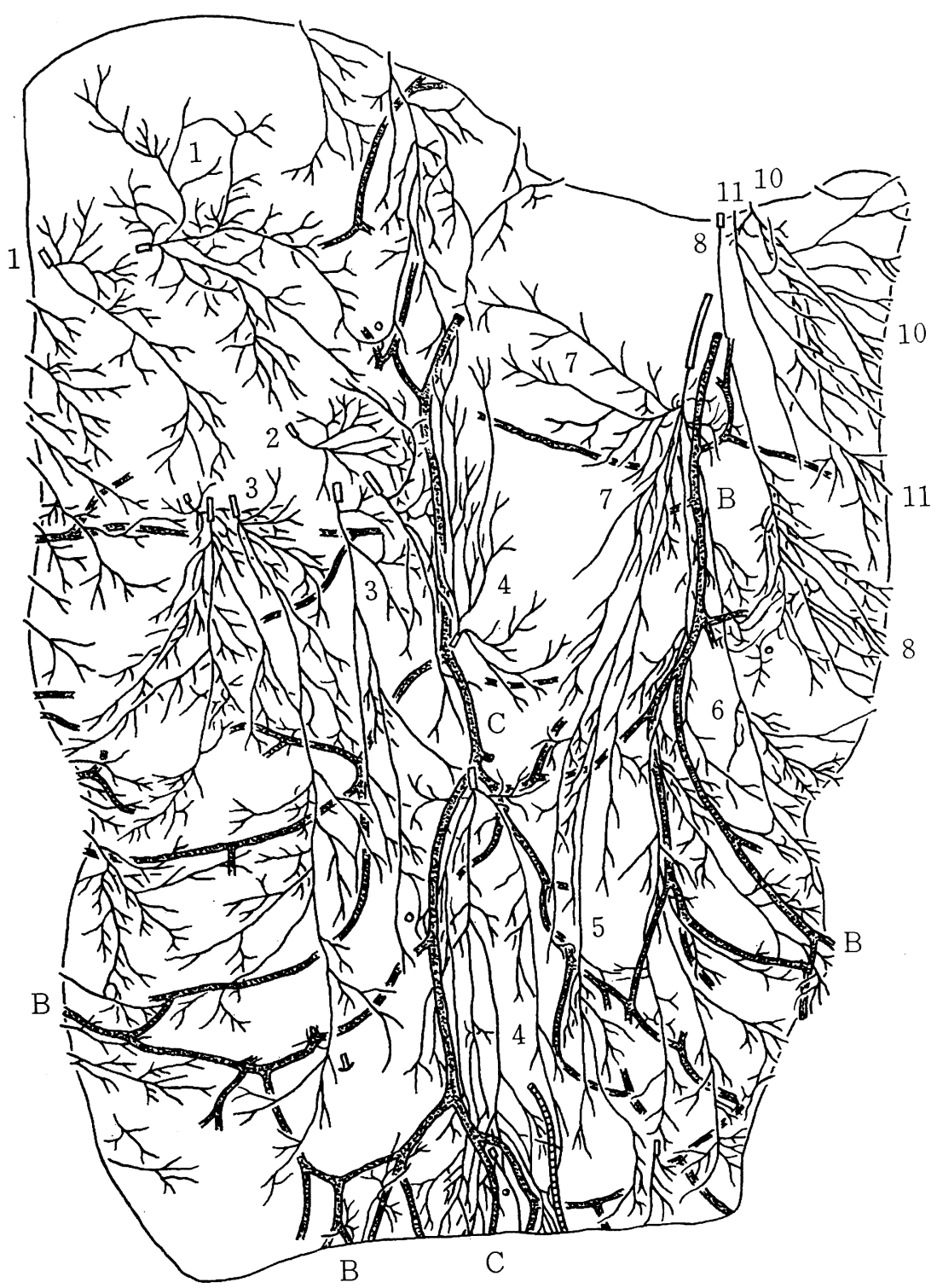

Fig. 2. Left upper extremity of a fetus. All the nerves and veins were followed under a stereoscopic microscope, by placing the skin flap upside down in water. Magnification, $\times 1$.

the ventral nerves.

The above-mentioned interrelations between the distribution of the cutaneous nerves and the course of the two superficial veins were also observed distally as far as the proximal half of the forearm. In the more distal region, however, the boundaries of distribution between the 
ventral and dorsal nerves gradually became indistinct, due to the appearance of anastomoses among adjacent nerves; and at the same time, identification of the cephalic and basilic veins became uncertain because of the many tributaries.

Embryologically, the developing limb bud projects from the trunk in a ventrolateral direction, and it therefore possesses ventral and dorsal surfaces, and also cranial or preaxial and caudal or postaxial borders. On the other hand, the cephalic and basilic veins develop as the marginal veins of the upper extremity, and the former passes along the cranial (radial) border of the limb, and the latter along the caudal (ulnar), according to Hochstetter (1891), Evans (1912) and Ura (1956). Woollard (1922) demonstrated this clearly in the pig by the injection method, and it has been quoted in many textbooks on embryology.

The divisional construction of the brachial plexus was described by Paterson (1887), Eisler (1895) and Bolk (1902), and they classified the nerves originating from the brachial plexus into ventral and dorsal derivatives. They described this especially for the muscular nerves of the plexus. According to the present authors, however, not only the muscular nerves but also the cutaneous ones can be classified into the two above-mentioned divisions. Generally, to decide the division to which the nerve under consideration belongs, all the findings concerned should be examined including the origin at the plexus, the course, anastomosis with adjacent nerves and distribution. Table 1 gives a classification of the cutaneous nerves based on previous work by the authors. The above-mentioned findings obtained in this study concerning the positional relations between the marginal veins and the distribution of the ventral and dorsal cutaneous nerves can thus be reasonably understood embryologically.

Since Voigt (1864) postulated a demarcation line of the skin based on the distribution of the cutaneous nerves, Eisler described the border line of distribution between the nerves derived from the ventral and dorsal divisions of the brachial plexus, and extended this onto the trunk. Eisler's line in the upper extremity almost coincides with that of the present authors, but the latter demonstrated the course of the line more clearly by the superficial veins.

2. Overlapping of distribution between adjacent cutaneous nerves

According to the clinical and physiological investigations of Sherrington (1893) and Foerster (1929, 1936), the distribution areas of adjacent cutaneous nerves overlapped each other to a considerable extent. However, such a broad overlap was not

Table 1. Classification of the cutaneous nerves of the arm and forearm into ventral and dorsal divisions of the brachial plexus.

\begin{tabular}{|c|c|}
\hline ventral division & dorsal division \\
\hline $\begin{array}{l}\text { 1. anterior branch of intercostobrachial } \\
\text { nerve (Icb-a) }\end{array}$ & $\begin{array}{l}\text { 1. posterior branch of intercostobrachial } \\
\text { nerve (Icb-p) }\end{array}$ \\
\hline $\begin{array}{l}\text { 2. anterior brachial cutaneous nerve of } \\
\text { medial antebrachial cutaneous nerve ( } \mathrm{Cba})\end{array}$ & 2. medial brachial cutaneous nerve $(\mathrm{Cbm})$ \\
\hline 3. lateral antebrachial cutaneous nerve (Cal) & 3. superior lateral brachial cutaneous nerve \\
\hline \multirow[t]{2}{*}{$\begin{array}{l}\text { 4. anterior branch of medial antebrachial } \\
\text { cutaneous nerve (Cam-a) }\end{array}$} & $\begin{array}{l}\text { 4. ulnar branch of medial antebrachial } \\
\text { cutaneous nerve }\end{array}$ \\
\hline & $\begin{array}{l}\text { 5. brachial and antebrachial cutaneous } \\
\text { nerves of radial nerve }\end{array}$ \\
\hline
\end{tabular}


observed in the present study, as shown in the figures. The authors concluded therefore that each cutaneous nerve had its own proper distributive area and no other nerves supplied the same region. Actually, a few anastomoses between adjacent nerves were observed, but their number was not great at least in the arm and the proximal half of the forearm, and they were found only among fine ramifications near the terminal distribution. The overlapping of distribution due to these anastomoses could thus not be so wide as Foerster suggested. Such anastomoses gradually increased in number as the nerves approached the wrist. As shown in Figs. 1 and 2, some branches of the posterior brachial cutaneous nerve (of the radial) were distributed overlapping with adjacent nerves, but most of these supplied the overlying deep fascia and so were not cutaneous in the real sense.

In the upper extremity where all the supplying nerves pass thraugh the plexus, dermatomal overlap in the peripheral distribution would be quite natural, each nerve being composed of several segmental nerve roots. Forester examined materials from persons who suffered injury during the world war and stated that each cutaneous nerve had its own "Maximalgebiet" and "Autonom-gebiet" in distribution. The former meant the total area of distribution of the cutaneous nerve, but most of it overlapped with adjacent nerves. The latter represented a small part of the former where only the nerve under consideration was distributed, with no other nerves supplying it. Foerster showed that, for example, the radial nerve usually had no Autonom-gebiet, most of the distributive area overlapping with adjacent nerves. Foerster's results were described in the textbooks of anatomy by Braus \& Elze and Hollinshead. On cutaneous innervation, discrepancies of description between anatomical findings and physiological or clinical ones have been discussed previously. Besides differences in the techniques of investigation, Elze (1957, 1961) emphasized that anatomists dissected the nerves under the skin (in the subcutaneous tissue), while clinicians and physiologists examined those on the surface of the skin.

3. The anterior axial line

In the ventral surface of the arm and forearm, a definite line has been described by Sherrington, Foerster and Keegan \& Garrett (1948) based on clinical and physiological experiments. They termed it the anterior axial line, and according to them, it passed in almost the median part of the upper extremity and presented a border line in the distribution of nerves derived from the discontinuous dermatomes. In the present study, the authors were able to demonstrate it anatomically from the viewpoint of the distribution of the cutaneous nerves, and considered it as none other than the border line of distribution of the following two nerve groups. One was the nerves derived from the lower segments of the brachial plexus (C8, T1, T2) which were distributed to the region medial to this line: the nerve Icb-a, Cba and the anterior branch of the medial antebrachial cutaneous nerve (Cam-a) belonged to this group. The cutaneous nerves from the axillary and the radial nerves and also that of the musculocutaneous nerve ( $\mathrm{Cal}$ ) belonged to the other group which originated from the upper segments of the plexus $(\mathrm{C} 5, \mathrm{C} 6, \mathrm{C} 7)$, and the distributive area was lateral to this line. In general, no connections were found between the above two groups. Thus, the course of the anterior axial line which was demonstrated by physiological and clinical methods in the living body could be clearly determined anatomically. As seen in Fig. 3, in the proximal half of the arm the course of the anterior axial line almost coincided 

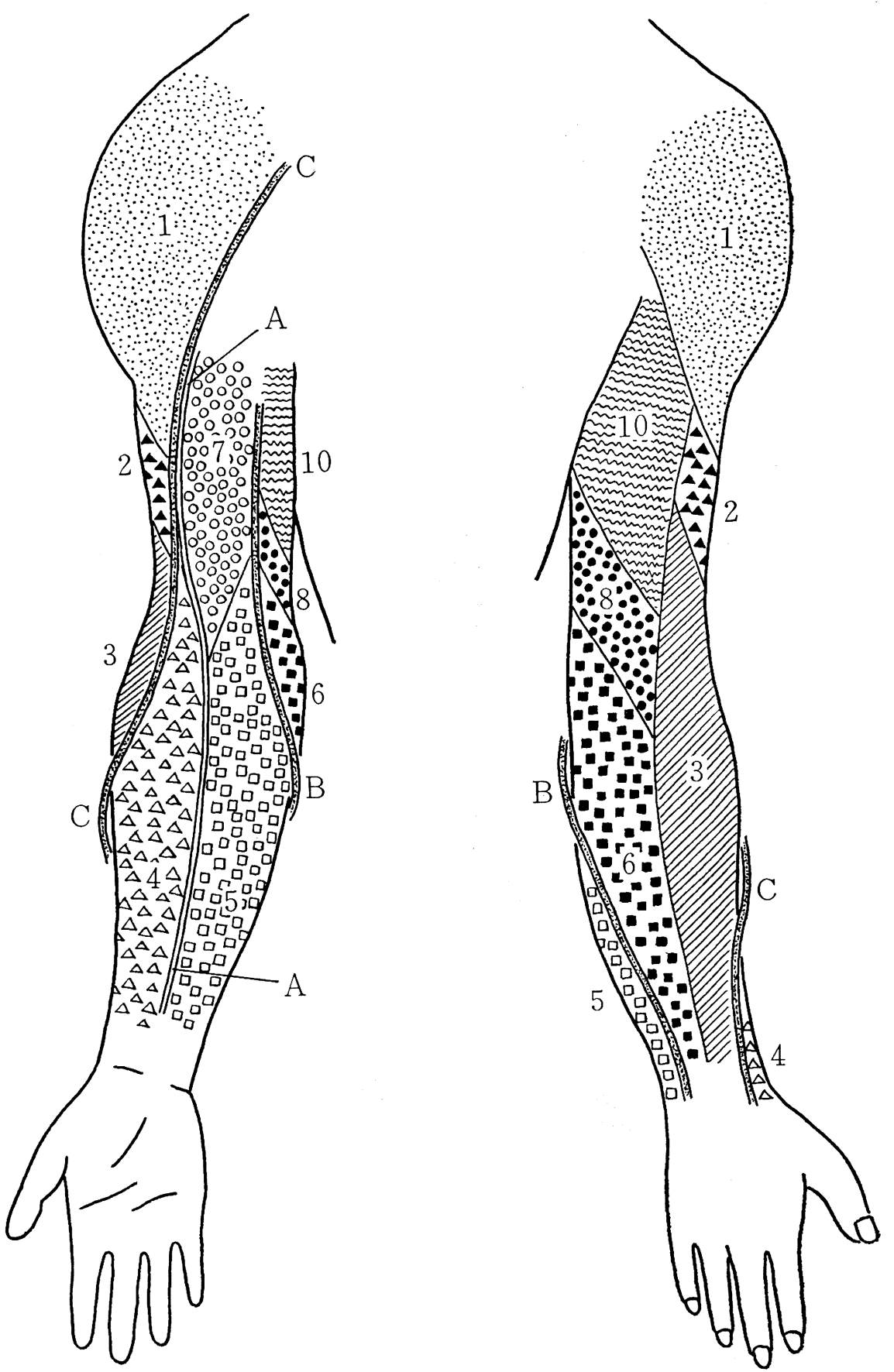

Fig. 3. Schematic representation of the interrelation among the distributions of each cutaneous nerve, the cephalic and basilic veins and the anterior axial line. 
with that of the cephalic vein because, as mentioned above, the cephalic vein marked the boundaries of distribution between $\mathrm{Cba}$ and Icb-a, both of which were ventral in nature and also derived from the lower segments of the brachial plexus, and the cutaneous branches of the axillary and the radial nerves which originated from the dorsal division and also from the upper segments of the plexus.

In the distal half of the arm, the axial line passed anatomically in between the distributive areas of $\mathrm{Cal}$ laterally and $\mathrm{Cba}$ or Cam-a medially, the former being derived from the ventral division and also the upper segments of the plexus, and the latter from the ventral and lower. One characteristic feature of this region as compared to the proximal part of the arm, was that the course of the line did not coincide with that of the cephalic vein, because the vein passed more laterally in between the distributive areas of $\mathrm{Cal}$ (ventral nature in the plexus) and the radial nerve (dorsal).

In the forearm, the axial line was considered to pass in the border line of the distributive areas of Cam-a (lower segment nerve of the plexus) medially and Cal (upper segment nerve) laterally.

\section{Acknowledgements}

The authors wish to express their appreciation to Prof. M. Yamada, Department of Anatomy, Kanazawa University, and also to Prof. T. Sato, Department of Anatomy, Tokyo Medical and Dental University, for providing them with valuable papers, the former that of Bolk (ref. number 1) and the latter that of Voigt (ref. number 17).

\section{References}

1) Bolk, L.: Der Plexus cervico-brachialis der Primaten. Petrus Camper. 1:371567, 1902.

2) Eisler, P.: Die Homologie der Extremitäten. Abhandlungen der Naturforschenden Gesselschaft zu Halle. 19: 1-258, 1895.

3) Elze, C.: Ergebnisse, Kasuistik und Diskussionen. Headsche Zone und Dermatome. Nervenarzt. 28: 465-469, 1957.

4) Elze, C.: Die anatomischen Grundlagen der Headschen Zonen. Zeitschr. f. Anat. u. Entwicklgsch. 122: 402-413, 1961.

5) Elze, C.: Allgemeine Metamerie des Rumpfes. Braus, H. Anatomie des Menschen. Bd. 3. 2-Auflage. 95-112, 158. Springer-verlag. Berlin. 1960.

6) Evans, H.M.: The development of the vascular system. Keibel, F. and Mall, F.P. Manual of Human Embryology. vol. 2. 687-698. Lippincott. Philadelphia. 1912.

7) Foerster, O.: Die kutanen Distributionsgebiete der sensiblen Nerven. Handbuch der Neurologie. Erganzungs-Bd. zweiter Teil. von Lewandowsky. 815-856, 1929.

8) Foerster, O.: Die Dermatome. Bumke und Foerster. Handbuch der Neurologie. Bd. 5. 246-285, 1936.

9) Hochstetter,F.: Über die Entwicklung der Extremitäts-venen bei den Amnioten. Morph. Jahrb. 17: 1-43, 1891.

10) Hollinshead, W.H.: The back and limb. Anatomy for surgeons. vol. 3. 248-257. Harper \& Row. New York. 1966.

11) Kasai, T. and Yamamoto, N.: The medial brachial cutaneous nerve and the intercostobrachial nerve. Acta Anat. Jap. $41: 29-42$, 1966. (in Japanese)

12) Kasai, T. and Chiba, S.: Further observations on the cutaneous nerves to the upper arm arising from the medial cord of the brachial plexus. Acta Anat. Jap. $55: 8-22,1980$. (in Japanese)

13) Keegan, J. J. and Garrett, F.D.: The segmental distribution of the cutaneous nerves in the limbs of man. Anat. Rec. 107: 409-437, 1948. 
14) Paterson, A.M.: The limb plexus of mammals. J. Anat. Physiol. 21 : 611-634, 1887.

15) Sherrington, C.S.: Experiments in examination of the peripheral distribution of the fibers of the posterior roots of some spinal nerves. Phil. Trans. Roy. Soc. London. Ser. B. 641-763, 1893.

16) Ura, R.: Kontribuo al ontogenio de vazsistemo de antauaj membroj, precipe ce hynobius naevius-unu provo solvi membro-problemon. Okajima's Folia Anat. Jap. 28: 257-285, 1956.

17) Voigt, C.A.: Beiträge zur Dermatoneurologie, nebst der Beschreibung eines Systems neu entdeckter Linien an der Oberfläche des menschlichen Körpers. 140, 1862.

18) Woollard, H.: The development of the principal arterial stems in the forelimb of the pig. Contributions to Embryology. 14 : 139-154, 1922. 